\title{
Erratum to: Effect of dew point during heating on selective oxidation of TRIP steels
}

\section{Metall. Res. Technol. 114, 609 (2017) DOI: 10.1051/metal/2017070}

Libin $\mathrm{Liu}^{1,2}$, Guangrui Jiang ${ }^{2,3, *}$, Haiquan Wang ${ }^{2,3}$, and Huaxiang Teng ${ }^{2,3}$

${ }^{1}$ State Key Laboratory for Advanced Metals and Materials, University of Science and Technology Beijing, Beijing, PR China

2 Shougang Research Institute of Technology, Beijing, PR China

${ }^{3}$ Beijing key Laboratory of Green Recyclable Process for Iron \& steel Production Technology, Beijing, PR China

Received: 9 October 2017 / Accepted: 10 October 2017

The affiliations of the authors were incomplete, we complete them in this Erratum.

\footnotetext{
* e-mail: guangrui82@qq. com
} 